\title{
Status Quo and Improvement of Sino-Foreign Cooperative Education System in China
}

\author{
Feng Xiao, Risheng Zhong* \\ Guangdong University of Foreign Studies, Guangzhou, China \\ Email: ^Sunny@gdufs.edu.cn
}

How to cite this paper: Xiao, F., \& Zhong, R. S. (2020). Status Quo and Improvement of Sino-Foreign Cooperative Education System in China. Open Journal of Social Sciences, 8, 84-94. https://doi.org/10.4236/jss.2020.812008

Received: November 27, 2020

Accepted: December 8, 2020

Published: December 11, 2020

Copyright $\odot 2020$ by author(s) and Scientific Research Publishing Inc. This work is licensed under the Creative Commons Attribution International License (CC BY 4.0).

http://creativecommons.org/licenses/by/4.0/

(c) (i) Open Access

\begin{abstract}
In the new era, Sino-foreign cooperative education requires new actions. To be specific, relevant systems should be formulated and implemented. As for the current Sino-foreign cooperative education system, on the one hand, China actively promotes the development of Sino-foreign cooperative education with both laws and policies. On the other hand, the quality of Sino-foreign cooperative education does not match its increase in quantity, which results from many existing problems in current systems. Therefore, efforts should be made to establish and improve relevant legal systems, strengthen government supervision, and coordinate Sino-foreign educational cooperation in an overall manner in the new era. These improvement solutions will help promote increase in both the quantity and the quality of school running, train international talents with national consciousness, serve the Belt and Road, and build a community of a shared future for mankind.
\end{abstract}

\section{Keywords}

Sino-Foreign Cooperative Education, Status Quo of Systems, Solutions for Improvement

\section{Introduction}

Sino-foreign cooperative education, an education mode which combines Chinese education with foreign education, is increasingly becoming an integral part of China's educational cause under the guidance of laws and policies and with the support of the government. It plays a key role in nurturing international talents. Sino-foreign cooperative education system has obvious advantages, but still needs improvements on the other hand. With the construction of the Belt and Road national strategy and the community with a shared future for mankind, Sino-foreign cooperative education system will continue to develop in the future 
and have a more promising future.

\section{Status Quo and Advantages of Sino-Foreign Cooperative Education System in China}

\subsection{Status Quo of Sino-Foreign Cooperative Education System in China}

With China's accession to the WTO and opening-up, Sino-foreign cooperative education has flourished. In 1983, the Nanjing Architecture Vocational and Technical Education Center was set up under Sino-German cooperation. In 1986, the Johns Hopkins University-Nanjing University Center for Chinese and American Studies was set up under Sino-US cooperation. They are regarded as the start of Sino-foreign cooperative vocational education and higher education institution respectively. After more than 30 years of development, by December 2018, China has approved the establishment and launch of totally 2389 Sino-foreign cooperative education institutions and programs (Xiong, 2019).

The rapid development of Sino-foreign cooperative education is backed by a series of national laws and policies. First of all, in terms of laws on Sino-foreign cooperative education, there are the Regulations of the People's Republic of China on Sino-foreign Cooperative Education (hereinafter referred to as the Regulations) promulgated by the State Council in 2003, the Regulations for Implementing Non-governmental Education Promotion Law of the People's Republic of China promulgated by the State Council in 2004, and the Measures for Implementing the Regulations of the People's Republic of China on Sino-foreign Cooperative Education (hereinafter referred to as the Measures) promulgated by the Ministry of Education in 2004, which define the nature, establishment, organization and management of Sino-foreign cooperative education, and lay down and standardize its foundation and framework. Besides, under the guidance of basic laws, policies for Sino-foreign cooperative education keep emerging and keep pace with the times. Especially in recent years, under flexible policies, Sino-foreign cooperative education has developed rapidly and become an increasingly important force that cannot be ignored in China's education. The Outline of the National Medium- and Long-term Plan for Education Reform and Development (2010-2020) (hereinafter referred to as the Outline) sets a special chapter titled Expanding Educational Opening-up to include Sino-foreign cooperative education in the national education plan for the next ten years. Encouraged by the Belt and Road national strategy, China's educational institutions and universities looking for opportunities to conduct cooperative education with countries along the Belt and Road and actively "bring in" and "go out". The national strategy of building world-class universities and world-class disciplines brings enormous opportunities. Therefore, in 2016, the General Office of the CPC Central Committee and the General Office of the State Council issued the Several Opinions on Educational Opening-up in the New Era (hereinafter referred to as the Opinions); in 2016, the Ministry of Education issued the Actions 
to Promote Co-construction of Belt and Road Education (hereinafter referred to as the Actions); in 2017, the State Council issued the 13th Five-Year Plan for the Development of National Education (hereinafter referred to as the Plan). Sino-foreign cooperative education becomes standardized, systematic and normalized. Under the guidance of these systems, Sino-foreign cooperative education in China is developing rapidly at present, but on the other hand, there are still many difficulties in school running, mainly represented by unsatisfactory school running quality. The root cause for this is that there are quite a few problems in terms of system.

\subsection{Advantages of Sino-Foreign Cooperative Education System in China}

First, China's laws and policies strongly support Sino-foreign cooperative education. The Regulations specifies that China encourages Sino-foreign cooperative education that introduces high-quality foreign educational resources and encourages Sino-foreign cooperative education institutions to introduce internationally advanced courses. The Outline specifically sets a chapter titled Expanding Educational Opening-up to stress on the introduction of high-quality educational resources. The Opinions proposes broader opening-up and Belt and Road education initiative. The Action confirms the implementation of the Silk Road Cooperative Education Program. With the support and encouragement of corresponding national systems, Sino-foreign cooperative education has developed rapidly and become an increasingly important part of China's educational cause.

Second, China's policies expand Sino-foreign cooperative education. So far, under the guidance of national policies, there are various Sino-foreign cooperative education modes, including Sino-foreign cooperative education institutions and Sino-foreign cooperation programs. There are various cultivation modules, including mixed cultivation, segmented cultivation, one-way cultivation, two-way cultivation, etc. There are various disciplines, including science and engineering majors such as computer science and automation, as well as various arts majors such as international economy and trade, foreign languages, and so on. By January 2018, Sino-foreign cooperative education institutions and programs approved cover all levels and types of teaching, involving more than 200 majors in 12 disciplines including natural sciences, engineering sciences, humanities and social sciences and so on (Golden Luke, 2018).

Third, China's relevant systems standardize the order of Sino-foreign cooperative education. Standardizing the order of school running can not only safeguard legitimate rights and interests of education institutions, students and parents, but also ensure the quality of school running. At the beginning of Sino-foreign cooperative education, due to the lack of national laws, policies and norms, everything was in chaos. Later, China made great efforts to rectify this situation by promulgating laws such as the Regulations and the Measures, and policy notices such as the Notice of the Ministry of Education on Further Regulating the Order of Sino-Foreign Cooperative Education and the Notice on the 
Evaluation of Sino-foreign Cooperative Education which have yielded many results. In 2017, the State Council issued the Plan, continuing to improve relevant systems. It strictly examined the establishment of Sino-foreign cooperative education institutions, introduced third parties for the evaluation of Sino-foreign cooperative education institutions, promoted the certification of school running certificates, and set up a supervision information platform. All these have produced remarkable results in standardizing the order of Sino-foreign cooperative education.

\section{Problems in Sino-Foreign Cooperative Education System in China}

\subsection{The Legal System Still Needs Improvements}

As mentioned above, at present, the most important law regulating Sino-foreign cooperative education in China is the Regulations promulgated in 2003. Although the Regulations plays an important role in promoting cooperative education, it can hardly meet the needs of cooperative education with the development of the times. For example, the Regulations stipulates that Sino-foreign cooperative education institutions are for public welfare undertaking, but under the development of market economy, Sino-foreign cooperative education tends to be market-oriented and commercialized. Its non-profit nature is diluted. We know that foreign education institutions are for commercial purpose in nature, but many Chinese education institutions also begin to pursue economic interests. How to guide cooperative education to correctly handle the relationship between non-profit nature and profitability has become a new focus, which is also the conflict between Chinese and foreign education. In addition, the Regulations itself has some shortcomings. For example, the Regulations encourages to introduce high-quality foreign educational resources, but there is no clear definition for what constitute high-quality foreign educational resources, and the standards are vague. Furthermore, the Regulations focuses on regulating the establishment, examination and change of Sino-foreign cooperative education institutions, but neglects the macro management of teaching activities. It is biased in this regard. We still have a long way to go to construct a whole-process supervision mechanism for Sino-foreign cooperative education. On the other hand, the Measures, which was originally formulated for the implementation of the Regulations, is more about principles. It is not so feasible. Most of its contents are about encouragement and advocacy, but it fails to clarify specific and corresponding legal responsibility. For example, on legal responsibility, the Measures does not specify penalty range and penalty amount. Its penalty intensity is weak. The fact that there are few cases with penalty in practice also confirms this viewpoint. In general, deficiencies of the Regulations and the Measures lead to more attention to examination than to management in Sino-foreign cooperative education. Although some achievements have been made in regulating the establishment and examination of Sino-foreign cooperative education institutions, there are some 
problems in the management of teaching activities and teaching quality. Deficiencies of legal systems directly affect the formulation and implementation of policies, so there are also the same problems in policies.

\subsection{Uneven School Running Level and Quality}

At present, the quality of Sino-foreign cooperative education cannot be positively correlated with the number of Sino-foreign cooperative education institutions. Besides, government supervision of school running quality is not in place. As a result, Sino-foreign cooperative education is faced with varying school running level and quality, which further restricts its long-term development. Specifically speaking, deficiencies in government supervision of Sino-foreign cooperative education are as follows. First, though there are strict regulations on approving Sino-foreign cooperative education institutions, but not much attention has been paid to follow-up supervision after the establishment of Sino-foreign cooperative education institutions, that is, whole-process supervision has not been in place. Second, education departments pay more attention to external periodic evaluation. Although there is regular evaluation, it cannot look deeply into daily teaching activities. Third, the government attaches great importance to the administration and program running of Sino-foreign cooperative education institutions, but ignores teaching team construction, curriculum content, textbook selection, backward teaching methods and so on. Fourth, there are limited supervision channels. The role of third-party institutions and schools in improving the quality of Sino-foreign cooperative education just gets ignored. Schools are a systematic institution, and education is also a systematic program, so the government should comprehensively control and supervise them. Insufficient supervision cannot ensure school running quality, let alone the sustainable development of Sino-foreign cooperative education. This can be proven by what actually happen these years. In addition, the fact that government supervision is not in place also reflects incompetency in governing Sino-foreign cooperative education. Sino-foreign cooperative education to some extent is an import. China introduces foreign educational resources, while the government lacks management experience in integrating local education with foreign education, which is proven by defective systems and insufficient supervision on the implementation of systems.

\subsection{Cooperative Education Still Cannot Coordinate Sino-Foreign Educational Conflicts}

Sino-foreign cooperative education in China has developed more rapidly after China's accession to the WTO. The number of Sino-foreign cooperative education institutions has been increasing. The number of programs has been increasing year by year. Many cooperation achievements have been achieved. However, this period of rapid development has been just over ten years. The integration between China's education and international education is still in the 
early stage, and the cooperation between the two sides is under exploration and running-in, and has not yet achieved big results. On the one hand, China's education system is quite different from that of European and American countries. In recent years, Sino-foreign cooperative education has encountered many conflicts and contradictions, such as different teaching concepts, diversified school running modes, asymmetric information, and conflicts between the non-profit nature and industrialization of education. Moreover, it is difficult to solve these problems only by universities of both sides. Instead, countries should coordinate to strengthen top-level design. At present, China pays more attention to domestic educational norms while not much to Sino-foreign educational coordination, which leads to continuous conflicts in Sino-foreign cooperative education and restricts further Sino-foreign education exchanges and cooperation. For example, unqualified Sino-foreign cooperative education programs keep emerging as China lacks information about foreign universities. Another example is the conflict between the non-profit nature of Sino-foreign cooperative education institutions and the profitability of foreign education institutions. For foreign higher education institutions, commercial profits or economic interests are one of the main motivations for their international education service trade (Lin \& Liu 2007). This is contrary to the Regulations, which stipulates that Sino-foreign cooperative education institutions should be for public welfare. On the other hand, Sino-foreign cooperative education also balances education sovereignty and educational internationalization and globalization. It is inevitable that $\mathrm{Si}$ no-foreign cooperative education will bring an impact on education sovereignty. The key lies in how to reduce the impact and cultivate high-level talents with both ethnic and national consciousness as well as international vision in the tide of education internationalization. Obviously, China still needs institutional improvements in this aspect.

\section{Suggestions on Improving Sino-Foreign Cooperative Education System in China}

The report of the 19th National Congress of the Communist Party of China pointed out that "with long-term efforts, socialism with Chinese characteristics has entered a new era, which will have an important historic bearing on China's future". In this new era, Sino-foreign cooperative education will take on a new look. Under the guidance of the new era, Sino-foreign cooperative education should further open up education, cultivate international talents for the new era, and contribute to the Belt and Road Initiative and a community with a shared future for mankind. The development prospect of Sino-foreign cooperative education depends on national policies to a large extent, which is also determined by China's political system (Li, 2011). Therefore, Sino-foreign cooperative education system in the new era should be further improved and deepened. The main line running through it should be equal emphasis on quality and quantity, so as to cultivate international talents with national consciousness in the new era to serve national development. 


\subsection{Consolidate the Foundation for Cooperation: Establish and Improve Relevant Legal Systems}

Laws can pave the way for Sino-foreign cooperative education. At present, the Ministry of Education is revising the Regulations. Therefore, comprehensive laws and regulations for Sino-foreign cooperative education will not be far behind. To be specific, the following measures can be taken to improve relevant legal systems for Sino-foreign cooperative education. First, we can revise the Regulations and the Measures to improve the basic legal guarantee for $\mathrm{Si}$ no-foreign cooperative education. First of all, we should balance the non-profit nature and market behavior of Sino-foreign cooperative education institutions. On the one hand, we should regulate their market behavior and strengthen the control over Sino-foreign cooperative education norms, while recognizing their non-profit nature. On the other hand, we should improve relevant regulations to allow reasonable returns and guide and supervise the pursuit of economic benefits of Sino-foreign cooperative education institutions by legal means. Second, we should formulate specific and feasible rules and guidelines. Principles can't facilitate practical implementation much. In particular, the Measures should be more refined so as to clarify legal responsibility with clear reward and penalty provisions. For example, in Chapter 5, Administration and Supervision, the wording "give administrative sanctions according to law" is frequently used for violation of the Measures. For the five acts violating Article 57, only "a warning or a fine of less than 30,000 yuan" is given. Third, we should emphasize whole-process supervision of school running. The current emphasis on examination is justified, but laws should also focus on teaching and administrative activities after these institutions and programs have been established and held from the beginning to the end. Furthermore, laws related to Sino-foreign cooperative education should be integrated with China's education law system. Although Sino-foreign cooperative education has its particularity, it is still a part of China's education system and should abide by and implement China's education laws and regulations. There should be no exceptions. For example, Sino-foreign cooperative education institutions should comply with the Regulations of the People's Republic of China on Academic Degrees, the Interim Provisions on the Establishment of Ordinary Undergraduate Schools and so on in respect of degree awarding and major setup. Therefore, in the future, it is very necessary to bring Sino-foreign cooperative education institutions into China's education law system, and include them into corresponding laws and regulations. Finally, we should improve the linkage and coordination between the Regulations and the Measures and other laws. China used to pay more attention to specialized laws such as the Regulations and the Measures. In practice, it was easy to ignore non-education laws related to advertising, foreigner management, taxation and so on in Sino-foreign cooperative education, which is not conducive to the all-round standardization of Sino-foreign cooperative education. Therefore, other legal matters concerning Sino-foreign cooperative education should be 
clearly defined and supplemented or emphasized in the Regulations and the Measures, so as to form a systematic legal basis.

\subsection{Provide Guarantee for Cooperation: Strengthen Government Supervision to Improve School Running Quality}

The key to Sino-foreign cooperative education is whether we can introduce high-quality educational resources and guarantee the development and utilization of resources introduced in terms of system and mechanism (Wang \& Li, 2013). Government supervision is particularly important to ensure high-quality educational resources. With the promotion of the Belt and Road national strategy and the incorporation of a community with a shared future for mankind into the Constitution, there will be more and more Sino-foreign cooperative education institutions and programs in the future. Therefore, government supervision is definitely necessary. On the one hand, in the process of globalization, it should be the focus of future laws and policies to adopt more relaxed policy requirements and standards for the qualification of school-running entities, improve examination and approval procedures, and establish a sound information disclosure system, so as to increase the number of Sino-foreign cooperative education institutions. On the other hand, in the future, China should strengthen government supervision. To be specific, the government should strengthen its supervision and support the development of third-party institutions to ensure external evaluation, encourage self-evaluation of institutions, and disclose regulatory information, so as to improve school running quality and level. First of all, after summarizing current experience, the government should actively improve its management ability, maintain strict examination and approval, and comprehensively supervise Sino-foreign cooperative education. It should pay attention to teaching activities, improve teachers' quality, adjust course contents, strengthen school running quality, and build cooperative education withdrawal mechanism. With these measures, its supervision work can be consistent and run through the whole process of school running. Secondly, the government should promote the development of third-party institutions and promulgate policies to guide them to improve relevant quality assessment standards and procedures, so as to form a standardized quality assessment system and provide guarantee for Sino-foreign cooperative education quality. Furthermore, education quality depends a lot on schools, so the government should promote schools to conduct self-assessment, establish and improve internal teaching quality guarantee mechanism and give play to the role of students in teaching assessment so as to enhance supervision. Finally, information disclosure is the best for supervision. By establishing a supervision platform for Sino-foreign cooperative education to disclose the government's supervision, third-party assessment results, and schools' self-assessment, we can not only protect and safeguard the public's right to know and supervise, but also improve school running quality. To improve Sino-foreign cooperative education, it is necessary to construct a diversified supervision mechanism and form an effective supervision system. In this way, we 
can strengthen the control of school running quality and improve school running level.

\subsection{Grasp the Key to Cooperation: Coordinate Sino-Foreign Cooperative Education}

The particularity of Sino-foreign cooperative education lies in the combination of Chinese education and foreign education. "Conflicts of interest may exist between importers and exporters." (OECD, 2004) However, the coordination necessary can't be satisfied by Chinese and foreign education institutions alone. Countries should coordinate to strengthen top-level design. In particular, under the requirements of the Belt and Road national strategy and a community with a shared future for mankind, we should focus on the common development with the world, strengthen cooperation and exchanges with governments of various countries, break through difficulties in Sino-foreign cooperative education, and deepen cooperation, so that both sides can seek common ground while reserving differences and finally achieve a win-win situation. First of all, to know yourself and your counterpart is the prerequisite for Sino-foreign cooperative education. First of all, China should, based on the status quo of China's education, comprehensively understand foreign educational policies, seek the starting point for cooperation and interest coordination, and finally promote policy convergence in Sino-foreign cooperative education. Second, the government should thoroughly investigate and learn foreign educational institutions, effectively evaluate and certify them, develop an information inquiry system for foreign educational institutions and programs, and define standards for foreign educational resources introduced to China to ensure the introduction of high-quality educational resources. Third, we should give full play to the role of education offices (groups) of Chinese embassies and consulates abroad (Lin, 2012). Education offices (groups) of Chinese embassies and consulates are a bridge of communication between China and foreign countries in educational cooperation. We should give full play to their role in investigating educational resources in the country where they are located and coordinating the institutional construction for Chinese and foreign education, so as to provide guidance for Sino-foreign cooperative education. Furthermore, we should correctly handle educational sovereignty in Sino-foreign cooperative education. In particular, education is related to major issues such as national sovereignty, social morality and inheritance of national culture. Governments of various countries are very cautious in opening up their respective education markets (Wang, 2005). This requires China to strengthen the standardization of Sino-foreign cooperative education system according to WTO rules, global education governance rules and international education rules, but this does not mean that we should tighten Sino-foreign cooperative education policies or restrict the entry of foreign education. Instead, we should further improve standards for introducing high-quality educational resources, improve school running examination contents and procedures, establish and improve school running quality guarantee system, pay at- 
tention to teaching contents, and attach importance to the cultivation of international talents with ethnic and national consciousness. Besides, we should timely summarize experience in Sino-foreign cooperative education, and actively participate in the formulation of rules for educational internationalization when "going out", so as to share China's ideas with the world.

\section{Conclusion}

In the new era, Sino-foreign cooperative education has a broad prospect. It plays a unique role in the construction of the Belt and Road and a community with a shared future for mankind. What China should do is to improve relevant systems to support and promote its further development. With social development, laws and policies should be more detailed and specific, and focus on concretely improving school running quality and cultivating international talents with national consciousness. In conclusion, to improve school running level and ensure school running quality, the basis lies in the further improvement of relevant laws is the basis and the key lies in overall planning and coordination of Sino-foreign cooperative education, guaranteed by improved government supervision and school running quality. The construction of the Belt and Road has also brought new opportunities and challenges for Sino-foreign cooperative education. How to seize these opportunities, establish supporting systems, deepen the reform of Sino-foreign cooperative education models, and optimize Sino-foreign cooperative education methods are also important topics that deserve further discussion. Due to the space limitation of this paper, the author will not go into these in depth. To sum up, the author expects that the government and Chinese and foreign educational institutions can make their efforts to promote the healthy and sustainable development of Sino-foreign cooperative education in China, thus providing steady power for the common progress of China and the world.

\section{Conflicts of Interest}

The authors declare no conflicts of interest regarding the publication of this paper.

\section{References}

Golden Luke (2018). The Reform of Sino-foreign Cooperative Education Starts Again. China Education Daily, 03-23-2018.

Li, X. H. (2011). Research on Sino-foreign Cooperative Education from the Perspective of Institutional Changes of Higher Education. Educational Research, 32, 54-58.

Lin, J. H. (2012). Research on the Introduction of High-Quality Educational Resources in Sino-foreign Cooperative Education. Educational Research, 33, 34-38+68.

Lin, J. H., \& Liu, Z. P. (2007). Reasonable Introduction and Effective Utilization of High-Quality Higher Educational Resources in Sino-Foreign Cooperative Education. Educational Research, No. 5, 36-39+50.

OECD (2004). International and Trade in Higher Education: Opportunities and Challenges. Paris: Organization for Economic in Cooperation and Development. 
https://doi.org/10.1787/9789264015067-en

Wang, F. L. (2005). Motivations and Development Countermeasures of Sino-foreign Cooperative Education. Journal of Yanshan University (Philosophy and Social Science Edition), No. 2, 32-37.

Wang, P., \& Li, L. L. (2013). The Development Course and Prospect of Sino-Foreign Cooperative Education Policies. Southeast Academic Research, No. 4, 242-248.

Xiong, J. H. (2019). Development Stage and Prospect of Sino-Foreign Cooperative Education. Study Times, 01-18-2019. 